Рагимова A.C.

ПЕРСПЕКТИВЫ РАЗВИТИЯ ИССЛЕДОВАНИЙ В ОБЛАСТИ МАЛОГО ПЛОТИНОСТРОЕНИЯ НА ОСНОВЕ ИСПОЛЬЗОВАНИЯ СТОКА МАЛЫХ ГОРНЫХ РЕК ДАГЕСТАНА

Ragimova A.S.

\title{
RESEARCH IN THE FIELD OF SMALL CONSTRUCTION OF DAMS AND PROSPECTS FOR THE USE OF DRAIN OF SMALL MOUNTAIN RIVERS OF DAGESTAN
}

В данной статье приведены результаты научного анализа актуальности исследований в области малого плотиностроения и определены перспективы использования стока мальх горных рек Дагестана.

Ключевые слова: удельная стоимость, удельные трудозатраты, технология возведения бетонных сооружений, малая плотина, градаџия бетонных плотин по категориям, проблемы в области малого плотиностроения, удельные показатели строительства монолитных бетонных плотин мальх категорий, малые и мельчайшие реки.

This article contains a scientific analysis of the relevance in the field of small construction of dams and prospects for the use of drain of small mountain rivers of Dagestan.

Key words: specific cost, specific labor costs, the technology of construction of concrete buildings, a small dam, gradation of concrete dams by category, problems in the field of small construction of dams, specific indicators of the construction of monolithic concrete dams of small categories, small and smallest rivers.

Введение. Известная в гидротехнике тенденция - увеличение удельной стоимости и удельных трудозатрат (на $1 \mathrm{~m}^{3}$ бетона) с уменьшением общего объема бетона в теле плотин долгое время рассматривалась с точки зрения качественного показателя. Например, не было известно, насколько увеличиваются указанные выше и другие удельные показатели с уменьшением объема бетона в определенных диапазонах. Или, где проходит граница, когда удельные показатели начинают заметно возрастать с уменьшением объема бетона в теле плотин при строительстве их по известным методам и технологиям.

Отдельные известные случаи показывали, что в одних и тех же региональных условиях стоимость $1 \mathrm{~m}^{3}$ бетона плотин малого объема в 2-3 раза и более, дороже, чем на больших и средних плотинах, а удельные трудозатраты 
(на 1 м³ бетона) выше в 3-10 раз. Однако эти факты не создавали цельной картины состояния дел в области технологии возведения малых плотин, и эта область оставалась «белым пятном» на «совести» гидротехников, включая и сам термин «малая плотина».

Учитывая вышеизложенное, с середины 1980-х годов начались исследования в области малого плотиностроения, и в этом направлении вырисовывались следующие задачи, которые необходимо было решать:

1. Оценить количественную базу строительства плотин малых категорий на малых реках, в частности, определить возможное количество малых плотин, которые можно построить на малых и мельчайших реках (Дагестана, Северного Кавказа и т.д.);

2. Установить особенности строительства плотин малых категорий (бетонных, земляных), с определением математической зависимости между объемом тела плотин и различных удельных показателей, включая количественную оценку понятия «малая плотина»;

3. Разработать высокотехнологичные в строительстве конструкции малых плотин, которые, по удельным показателям технологии возведения не уступали бы, а возможно и превышали показатели, полученные при строительстве больших и средних плотин;

4. Применить новые математические методы расчета устойчивости и прочности разработанных конструкций плотин, с целью установления наиболее оптимальных их параметров и предельно допустимых значений по высоте;

5. Разработать и апробировать на практике технологию возведения новых конструкций плотин, сравнить полученные результаты с существующими ныне технологиями возведения.

Решение вышеперечисленных задач началось с наиболее наукоемких направлений п.3 и п.4, т.е. - с разработки новых конструкций плотин и методов их расчета. В 1983-86 гг. были получены первые авторские свидетельства на изобретения по сборным бетонным плотинам и появились и первые публикации по новым конструкциям сборных плотин в центральных научных журналах. До 1992 года было получено 12 авторских свидетельства на изобретение сборных плотин, часть из которых позже была переведена в патенты.

В начале 1990-х годов были разработаны методы расчета для некоторых из конструкций сборных плотин, которые опубликованы в научных изданиях. Одновременно разрабатывалась и технология возведения сборных плотин, апробация которой впервые осуществлялась при строительстве первой в СССР сборной гравитационной плотины, построенной в Гунибском районе Дагестана в 1991 году, с публикацией полученных результатов в центральном журнале гидротехников $[1,2,3]$.

Основными итогами исследований в вышеуказанный период явились:

- разработка более 40 видов высокотехнологичных конструкций сборных подпорных сооружений, всех конструктивных типов, которые можно 
было возводить в 3-5 раз быстрее, по сравнению с монолитными вариантами;

- разработка технологии возведения и организации строительства новых плотин, которые позволяли достигнуть указанных выше показатели, заложенные в их конструктивных решениях;

- на основе метода «конечных элементов», разработаны математические модели расчета сборных бетонных плотин (на устойчивость и прочность), как дискретные области, где взаимодействие элементов происходит по швам между блоками;

- впервые построить полносборную бетонную гравитационную плотину, с апробацией на ней технологии возведения.

Постановка задачи. С целью дальнейших планомерных исследований в области конструкторско-технологических решений создания новых видов и типов плотин, необходимо было более детально изучить особенности строительства монолитных бетонных плотин в области «малых категорий», с целью выявления причин больших удельных показателей в этой области - при строительстве их по существующим методам и технологиям. Одновременно, необходимо было более аргументировано дать количественную оценку возможной базы строительства малых плотин на всех малых и мельчайших реках Дагестана. Это необходимо для того, чтобы знать, стоит ли заниматься данной проблемой вообще? Особенно это важно при взаимоотношениях с другими специалистами, имеющих возможность помочь в решении проблем в малом плотиностроении, т.е., ответить на задачи, поставленные в вышеуказанных п. 1 и п.2.

Исследования по этим пунктам вышеуказанных задач начались в середине 1990-х годов и к 2001 году получены первые значительные результаты.

Прежде всего, в градацию категорий бетонных плотин, предложенную ранее $[3,4]$, было внесено дополнение, т.е. самые малые плотины - объемом до $10 \mathrm{M}^{3}$ были отнесены к 1-й категории, объемом от 10 до 100 - во 2-й категорию и т.д., до 8-й категории - с объемом бетона более 10 млн.м³

Это позволило выделить область супер малых плотин, где удельные показатели в строительстве ожидались наибольшие. Затем доказать, что данная градация хорошо коррелируется со значимостью объектов для народного хозяйства, например, существует четкая взаимосвязь между объемом бетона в теле плотин и мощностью ГЭС, для которой построена эта плотина [4]. Аналогичная корреляция наблюдается и между объемом бетона в теле плотин и площадями мелиорирумых земель.

Методы исследования. Для исследования удельных показателей строительства монолитных бетонных плотин малых категорий с учетом реальных условий были рассмотрены более 30 створов на малых и мельчайших реках Дагестана (в Сулейман-Стальском, Карабудахкентском, Акушинском и Левашинском районах). Для 27 створов были составлены проекты плотин для реального строительства, которые в организации и технологии возведения учитывали местные условия. 
Объемы бетона плотин в рассмотренных створах находились в диапазоне от 6 до $3500 \mathrm{~m}^{3}$, ширина створов колебалась от 4 до 70 м, высота плотин от 3 до $20 \mathrm{M}$, среднегодовые расходы рек от 0,1 до $0,5 \mathrm{~m}^{3} / \mathrm{c}$, при максимальных

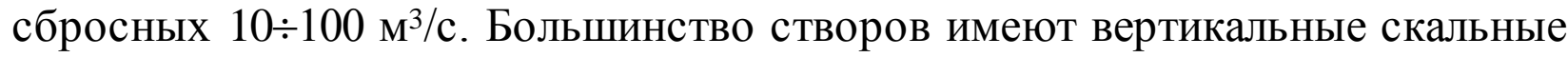
борта с аллювиальными отложениями в основании толщиной от 1 до 4 м. Все рассмотренные плотины, кроме одной, имеют водосливы на гребне.

По каждому виду плотин были получены общие и удельные показатели по трудозатратам, по стоимости, по срокам строительства и т.д. Причем, общие и удельные трудозатраты определялись в отдельности по видам и группам работ (буровзрывные и земельно-скальные; работы по отводу воды рек в строительный период; бетонные работы в створе и т.д.), а затем суммировались. Сметно-финансовые расчеты производились для строительномонтажных работ (CMP) и сводным сметам (удельные стоимостные показатели определялись в отдельности, по каждому виду смет). Общие и удельные сроки строительства определялись на основе оптимизированных календарных графиков работ.

Данными исследованиями была установлена взаимосвязь между объемом бетона в теле плотин с общими и удельными показателями по трудозатратам; стоимостным показателям; срокам строительства и т.д.; получены математические выражения данных зависимостей и другие количественные показатели.

Результаты эксперимента и их обсуждение. Полученные результаты были опубликованы [5] и они показывают, что при изменении (уменьшении) объема бетона в теле плотин от $3500 \mathrm{~m}^{3}$ до $6 \mathrm{~m}^{3}$, удельные трудозатраты приходящиеся на $1 \mathrm{~m}^{3}$ бетона увеличиваются от 4 до 44,5 чел.час/ $\mathrm{M}^{3}$ - по чисто бетонным работам от 4,1 до 54,3 чел.час/ м $^{3}$ - по бетонным работам и устройству мостовых переходов на гребне плотин и от 4,4 до 89,2 чел.час/ м $^{3}$ - по всем видам работ возведения плотин (с учетом водоотведения в строительный период, буровзрывных работ и т.д.). В этом же диапазоне, удельные стоимостные показатели по СМР и сводной смете, приведенные к 1 м 3 бетона, изменяются (увеличиваются) примерно в 4 раза.

Данные результаты показывают, что с изменением объема бетона от середины 4-й категории плотин (диапазон от 1 до 10 тыс. м $^{3}$ ), удельные трудозатраты повышаются в 11,1 раза по бетонным работам и в 20,3 раза - по всем видам работ в створе. При этом удельная стоимость объекта, приведенная к 1 $\mathrm{M}^{3}$ бетона, увеличивается примерно в 4 раза. Если сравнить эти данные с лучшими показателями, полученными при строительстве плотин 7-й категории (с объемом бетона от 1 до 10 млн.м³), например, с удельными трудозатратами, полученными при строительстве Саяно-Шушенской, Токтогульской и Чиркейской плотин, где они равнялись 1,3 чел.час/ $\mathrm{M}^{3}$ [6], то видно, что на плотинах малых категорий они выше от 3,1 до 34,2 раз.

Из вышеприведенного видно, насколько плохо обстоят дела в малом плотиностроении, если строить плотины малых категорий по существующим методам и технологиям, применяемых для больших плотин. Это сказывается 
и на удельной стоимости объекта, на удельных сроках строительства и т.д. Все это говорит о том, что необходимо продолжать поиск новых конструктивно-технологических решений строительства плотин малых категорий.

По исследованиям о возможном количестве малых плотин в Дагестане (количественная база) в настоящее время получены первые результаты.

Исследования производились с учетом количества малых и мельчайших рек в Дагестане (6248), их общей длины и средних уклонов рек в диапазонах высот в горах до 700 м; от 700 до 1200 м; от 1200 до 2000 м; от 2000 до 2500 м и более 2500 м. Количественная оценка проводилась в отдельности по малым и мельчайшим рекам бассейнов р.Сулак, р.Самур и самостоятельным рекам горно-предгорной зоны. Устанавливались уклоны рек в указанных выше диапазонах высот и бассейнам. С учетом среднегодовых расходов малых рек подбирались средние высоты плотин: для расходов $2 \div 8 \mathrm{~m}^{3} / \mathrm{c}-$ высотой до $30 \mathrm{M}$; для расходов $0,5 \div 2 \mathrm{M}^{3} / \mathrm{c}$ - высотой до 20 м и для расходов меньше 0,5 м3/с - высотой до 10 м.

С учетом возможного «вмещения» указанных высот плотин (верхних бьефов) на своих участках по длине рек, с учетом их уклонов, получены средние длины водохранилищ в разных высотных диапазонах, и в соответствии с этим вычислено возможное количество водохранилищ на всей длине всех рек.

Вывод. Теоретически возможное количество водохранилищ (плотин) указанных выше высот в сумме может быть порядка 150 тысяч. Однако не все плотины из этого количества можно возводить (или экономически целесообразно возводить) из-за освоенности земель в долинах рек, дорог у русел рек, скотопрогонов. Если проводить аналогию с гидроэнергетикой Дагестана, когда из 50,3 млрд. квт. ч. потенциальной энергии всех рек Дагестана, экономически целесообразной считается примерно 3-я часть (16 млрд. квт. ч.), тогда целесообразное количество плотин (водохранилищ) для всех возможных целей применения (орошение, малые ГЭС, водоснабжение, рекреация и т.д.), может быть принято порядка 50 тысяч. Это и есть та количественная база для малых плотин, которые можно построить в Дагестане.

Много это или мало? Если учесть, что на притоках р. Янцзы в Китае уже построено около 100 тысяч средних и малых плотин, то 50 тысяч возможных к строительству плотин в Дагестане не покажется - много. Но если учесть, что в 1960-1990 годы в Дагестане построено около 33 плотин высотой до 30 м (т.е. в среднем примерно 1 плотина в год), то это достаточно большая цифра. Если эту «целину» осваивать строительством по 100 плотин в год, то работы хватит на 500 лет!

Это достаточно большая база для целенаправленных исследований в этой области. Работы в этом направлении продолжаются, включая и строительство экспериментальных сборных бетонных плотин, которые, например, были построены на р. Акташ у г. Хасавюрт и р. Накхер в Левашинском районе. 


\section{Библиографический список:}

1. Сулейманов И.А-Г. Дагестанская сборная бетонная плотина. М., Гидротехническое строительство, №11, 1992.

2. Сулейманов И.А-Г., Муслимов Х. Строительство плотин на малых реках М., Гидротехническое строительство, №9, 1993.

3. Сулейманов И.А-Г., Соколов И.Б. О строительстве малых по объему сборных бетонных плотин. М., Гидротехническое строительство, №7, 1994.

4. Сулейманов И.А-Г., Гаджиева А.С. Общие соображения по плотиностроению и постановка задач исследований в области плотин малых категорий. Махачкала, Госком.РД по мелиорации и водному хозяйству, ДГТУ. Сб.статей, 1997.

5. Сулейманов И.А-Г., Гаджиева А.С. Особенности строительства бетонных плотин малых категорий. М., Гидротехническое строительство, №2, 2001.

6. Судаков В.Б., Толкачев Л.А. Современные методы бетонирования высоких плотин. М., Энергоатомиздат, 1988. 